\title{
C) Hitcastórica
}

Economia e crise sanitária na Província da Bahia: os casos da febre

$$
\text { amarela e cólera-morbo (I849 - I856) }
$$

\author{
Economy and health crisis in the Province of Bahia: the cases of yellow fever and \\ cholera-morbus (I849 - I856)
}

\section{Marcos Guedes Vaz Sampaio"}

Resumo: O presente artigo tem como objetivo analisar os impactos econômicos sofridos pela Província da Bahia durante a epidemia de febre amarela e a pandemia do cólera-morbo nos anos I850, mais precisamente, entre os anos de I849 e I856. A Província da Bahia, assim como grande parte do território brasileiro, vivenciou um período bastante dramático durante a primeira parte da década de I850, quando dois eventos sanitários importantes ocorreram num intervalo de tempo muito curto. Primeiro, na segunda metade do ano de I849, começava a epidemia provocada pela febre amarela trazida por uma embarcação estadunidense. Após um ano com elevado número de casos e mortes, a epidemia arrefeceu e permaneceu por meio de surtos que foram registrados até I857. Logo em seguida, no ano de I855, o cólera-morbo alcançou o Brasil após uma onda devastadora na Europa. Tanto a Província da Bahia, quanto o Brasil, enfrentaram uma crise sanitária ainda mais grave, com um número bastante elevado de vítimas fatais. Este estudo visa a contribuir para uma compreensão mais ampla dessas duas emergências sanitárias por meio de uma análise mais detida sobre seus desdobramentos econômicos na Província da Bahia, uma das mais atingidas e, até o momento, pouco estudada pela historiografia a partir dessa perspectiva. Para cumprir este objetivo, o estudo se amparou em pesquisa bibliográfica e documental. A primeira consistiu em uma revisão bibliográfica sobre o tema e, a segunda, se debruçou sobre as falas, mensagens e relatórios dos presidentes da Província da Bahia no período em tela. Utilizando-se de uma metodologia dedutiva por meio de um estudo de caso, a análise se baseou numa abordagem qualitativa, porém enriquecida por dados quantitativos para apresentar uma conclusão sobre o tema proposto.

Palavras-chave: Epidemias; economia; Bahia.

\footnotetext{
"Doutor em História Econômica pela Universidade de São Paulo (2006); professor associado do Instituto de Humanidades, Artes e Ciências (IHAC) da Universidade Federal da Bahia (UFBA), lecionando no Bacharelado Interdisciplinar em Humanidades e na área de concentração em Relações Internacionais.
} 


\section{C) GitistóróRICA}

Abstract: This article aims to analyze the economic impacts suffered by the Province of Bahia during the yellow fever epidemic and the cholera morbo's pandemic in the I850s, more precisely, between the years I849 and I856. The Province of Bahia, as well as much of the Brazilian territory, experienced a very dramatic period during the first part of the I850s, when two important sanitary events occurred in a very short period of time. First, in the second half of the year I849, the epidemic caused by yellow fever, brought by an American vessel, began. After a year with a high number of cases and deaths, the epidemic cooled and remained through outbreaks that were recorded until I857. Soon after, in I855, cholera-morbus reached Brazil after a devastating wave in Europe. Both the Province of Bahia and Brazil faced an even more serious health crisis, with a very high number of fatalities. This study aims to contribute to a broader understanding of these two health emergencies through a more detailed analysis of their economic consequences in the Province of Bahia, one of the most affected and, so far, little studied by historiography from this perspective. To fulfill this objective, the study was supported by bibliographical and documental research. The first consisted of a literature review on the topic and the second focused on the speeches, messages and reports of the presidents of the Province of Bahia in the period under review. Using a deductive methodology through a case study, the analysis was based on a qualitative approach, but enriched by quantitative data to present a conclusion on the proposed theme.

Keywords: Epidemics; economy; Bahia.

\section{Introdução}

O mundo está atravessando, desde o final de 2019, uma das maiores crises sanitárias da sua história. A pandemia ${ }^{\mathrm{I}}$ do novo coronavírus, o Sars Cov-2 (Severe acute respiratory syndrome Coronavirus 2), provoca uma doença denominada Coronavirus Disease I9, também conhecida pela sigla Covid-I9, uma doença sistêmica² que recebeu

\footnotetext{
I De acordo com a Organização Mundial da Saúde (WHO, 202I), uma epidemia ocorre quando uma doença, geralmente infecciosa, se dissemina atingindo um expressivo número de pessoas numa determinada região, país ou, até mesmo, um conjunto de países. Uma pandemia, por sua vez, ocorre quando uma epidemia atinge países em, pelo menos, três continentes. Por esta classificação, a disseminação da febre amarela no período em análise se constituiu numa epidemia, enquanto a disseminação do cólera-morbo foi uma pandemia.

2 A Covid-I9 foi classificada, inicialmente, como uma síndrome respiratória aguda grave, porém, segundo amplamente noticiado na imprensa nacional e internacional, à medida em que os estudos avançam, ela tem sido reclassificada como uma doença sistêmica.
} 
o número I9 em alusão ao ano de sua descoberta. Desde o seu começo no final do mês de dezembro de 20I9, a pandemia já vitimou mais de 3 milhões de pessoas no mundo. No Brasil, os números são, igualmente, impressionantes, totalizando mais de 380 mil pessoas. O número de contaminados no mundo ultrapassa 145 milhões de casos, enquanto no Brasil supera I4 milhões (WHO, 202I). Estes números aproximados tendem a aumentar bastante, uma vez que a pandemia ainda está em curso.

Se os números sobre a disseminação da doença e sua substancial letalidade impressionam, sob o ponto de vista econômico, os dados também são preocupantes. De acordo com o FMI, a economia mundial declinou 3,5\% no ano de 2020 (LEVY, 202I, p. 8), enquanto o Brasil registrou uma queda de $4, \mathrm{I} \%$ do seu $\mathrm{PIB}$, o que revela os efeitos perversos sobre a economia mundial e brasileira (FOLHA DE SÃO PAULO, 03/03/202I). Ainda de acordo com o FMI, as relações comerciais internacionais no ano de 2020 declinaram 9,5\% em seu volume de transações mercantis, quando comparado com o montante alcançado em 20I9. Para o ano de 202I, as projeções são de crescimento do PIB mundial de 5,5\%, enquanto o comércio exterior deve recrudescer $8,1 \%$. Enquanto a produção de riquezas começará um movimento de recuperação mais acentuada, as transações mercantis internacionais enfrentarão um processo mais lento de retomada, com resultado inferior à queda em 2020 (LEVY, 202I, p. 8).

O Brasil, segundo a Secretaria Especial de Comércio Exterior e Assuntos Internacionais (SECINT, 202I), obteve um desempenho ligeiramente melhor do que a previsão para o sistema mercantil internacional, com uma corrente de comércio que alcançou, em 2020, US\$ 368,75 bilhões, ante US\$ 402,73 bilhões obtidos no ano de 2019. Este resultado representa um declínio de $8,4 \%$, melhor, portanto, do que o desempenho da corrente internacional de comércio em escala global. Segundo a Associação de Comércio Exterior do Brasil (AEB, 202I), a corrente de comércio brasileira deve se recuperar de maneira substancial no ano de 202I, alcançando US\$ 405,65 bilhões, o que significa um crescimento de I0\% em relação a 2020.

Os números apresentados até aqui evidenciam, de um lado a tragédia humana vivenciada em escala global, durante a crise sanitária provocada pelo Sars Cov-2, mas, também, a recuperação econômica que se observa, à medida que a pandemia vai sendo controlada. O processo de retomada da economia mundial envolve uma série de fatores como as expectativas de empresários e investidores, que influenciam no recrudescimento dos investimentos privados, o restabelecimento das relações comerciais internacionais em níveis próximos aos que o mundo vivenciava no período 


\section{C) hitstsónilca}

pré-pandemia e o substancial papel desempenhado pelo Estado, amplificando seus gastos e investimentos, de modo a socorrer os mais diversos agentes econômicos afetados pela emergência sanitária, como para promover um choque contracíclico visando a estimular a demanda agregada nacional.

Crises sanitárias no passado, também foram dramáticas e tiveram impactos econômicos importantes. O presente artigo busca contribuir para a compreensão dos impactos econômicos nas crises sanitárias, por meio do uso do método dedutivo, a partir de uma análise qualitativa, porém com importante auxílio de dados quantitativos. $\mathrm{O}$ estudo de caso foi escolhido pela possibilidade de investigação dos efeitos de um fenômeno mais amplo sobre uma dimensão espacial reduzida, no caso, a epidemia de febre amarela e a pandemia de cólera-morbo, que afetaram diversos países, porém, neste artigo, sua observação e análise ficaram restritas aos desdobramentos na Província da Bahia. Esses eventos epidêmicos já foram objeto de pesquisas tanto dentro de uma perspectiva nacional, quanto regional, cobrindo parte importante das províncias do Império no oitocentos, incluindo a Bahia. Porém, este artigo se propõe a se debruçar sobre estes eventos em conjunto, dado que o intervalo de tempo entre elas foi de cinco anos, permitindo, assim, um estudo que envolva as duas emergências sanitárias, e com uma abordagem direcionada para os rebatimentos econômicos. Desse modo, este estudo busca preencher uma lacuna na historiografia sobre os impactos econômicos dessas crises sanitárias, analisadas em conjunto, sobre a economia de uma província. A pesquisa se amparou em fontes bibliográficas e documentais, realizando, inicialmente, uma revisão da literatura sobre o assunto para, num segundo momento, enriquecer e complementar o estudo com as falas, mensagens e relatórios dos presidentes da Província da Bahia.

$\mathrm{O}$ artigo resultante desse estudo está dividido em duas partes, além desta introdução e das considerações finais. A primeira parte se debruça, de maneira panorâmica, sobre a epidemia da febre amarela e a pandemia do cólera-morbo no Brasil na metade do século XIX, com o intuito de apresentar um quadro geral sobre a crise sanitária no país, a partir de um resgate da historiografia sobre o tema, mas acrescentando uma análise econômica. A segunda parte, por sua vez, centra sua análise nos mesmos eventos sanitários, porém com o recorte na Província da Bahia, entre os anos de I850 e I856, período de prevalência da emergência sanitária em solo baiano, entretanto concentrando sua análise nos efeitos econômicos sobre a economia provincial. 


\section{C) GitistóróRICA}

Um panorama da febre amarela e do cólera-morbo nos anos I850 no Brasil

O século XIX foi marcado pelo aumento expressivo na quantidade de epidemias, se comparado a períodos anteriores. Pesquisadores em História da Medicina encontraram uma explicação para essa mudança no padrão epidêmico: a expansão comercial e militar inglesa, principalmente na Ásia, e, em especial, na Índia. Segundo Le Roy Lauderie (1978)3 apud Franco (20I4, p. II8), a expansão comercial do Império Britânico levou o mundo a um processo de globalização que trouxe, como consequência do ponto de vista sanitário, a unificação microbiana. Witter (2007) corrobora essa interpretação, afirmando que a força motriz do surgimento e propagação de moléstias pelo mundo foi o aumento da circulação de pessoas e mercadorias no transcurso do oitocentos.

As inovações nos transportes que ocorreram no decorrer do século XIX, principalmente após o surgimento da navegação a vapor e das ferrovias, teve um caráter revolucionário para o cotidiano das sociedades. $\mathrm{O}$ desenvolvimento tecnológico nos transportes favoreceu o crescimento mais forte do comércio internacional, amplificando o intercâmbio de mercadorias e pessoas. A maior regularidade e o tempo mais curto de viagem eram as principais vantagens das máquinas a vapor que, em alguns casos, conseguiram diminuir o tempo de uma viagem em cerca de 70\%, como relata Mauro (1976, p. I80): “Graças ao vapor, a viagem de Nova Orléans a Pittsburgh foi reduzida de cem para trinta dias". Se por um lado, a revolução nos transportes trouxe importantes avanços econômicos, por outro facilitou a proliferação de doenças, que pulularam no decorrer do período oitocentista. É neste cenário de transformação significativa nos transportes e consequente encurtamento das distâncias, que o mundo registrou o crescimento substancial das epidemias, dentre elas a de febre amarela e do cólera-morbo, esta última terminou se transformando numa pandemia.

No Brasil, a febre amarela chegou bem antes do cólera e provocou sua primeira epidemia no país, ainda no século XVII, mais precisamente no ano de I685, na cidade de Recife. A forma como ela alcançou o território nacional não foi totalmente esclarecida, sendo o registro mais próximo, o que relatou Franco (1969, p. Io):

\footnotetext{
${ }^{3}$ LE ROY LAUDERIE, E. Um conceito: a unificação microbiana do mundo (séculos XIV - XVII). In: Le
} territoire de l'historien. Paris: Gallimard, 1978. 


\section{C) Hitistór RICA}

Ao contrário do que geralmente sucede, não existem referência sobre a doença em algum barco antes da eclosão da epidemia, ou que tenham desembarcado no porto tripulantes ou passageiros doentes. Quando a encontramos, já estava na zona portuária, fazendo a sua primeira vítima na pessoa de um empregado que conferia a mercadoria importada. De fato, contam as crônicas da época que, a 28 de novembro de $\mathbf{6} 685$, no Recife, um tanoeiro, ao abrir as barricas de carne, já podre, procedentes de São Tomé, adoeceu subitamente, passando a doença a quatro ou cinco pessoas que moravam na mesma casa, na rua da Praia.

A febre amarela também teria surgido na Bahia poucos meses depois, em abril de I686. Porém, após essa crise epidêmica, desapareceu, enquanto emergência sanitária, por mais de um século. Nesse ínterim, surtos isolados teriam acontecido sem provocar impactos mais significativos (FRANCO, I969). Em 30 de setembro de I849, uma epidemia de febre amarela ressurgiu no Brasil, começando pela Província da Bahia, atingindo principalmente estrangeiros, embora tenha se alastrado de maneira rápida entre a população local ${ }^{4}$. Ainda de acordo com Franco (I969, p. 27), essa epidemia durou I2 anos no Brasil, começando em I849 e terminando em I86I. Durante esse período, se disseminou pelo território nacional, por meio da navegação marítima. Da Bahia, o mal amarílico se deslocou para Pernambuco, chegando a esta província no dia 18 de dezembro, a bordo do brigue francês Alcyon. Dez dias depois, apareceu no Rio de Janeiro, permanecendo na capital do país por 59 anos (FRANCO, 1969, p. 28). De maneira sucessiva, a febre amarela foi contaminando pessoas em todas as províncias do Império ao longo dos anos, se configurando como uma das principais crises sanitárias da História do Brasil.

A chegada da febre amarela e, alguns anos depois, do cólera-morbo, provocaram uma mudança na postura governamental em relação à saúde pública. Antes dessas duas crises sanitárias, a assistência à saúde era uma ação de caridade, sobretudo a partir da Santa Casa de Misericórdia ou de ordens religiosas, que contavam com algum subsídio estatal ou doações de pessoas que ocupavam cargos políticos. Somente após a epidemia de febre amarela é que o governo imperial começou a organizar os serviços de saúde com as autoridades políticas regionais, como

4 FALLA que recitou o Presidente da Província da Bahia, Francisco Gonçalves Martins, n’Abertura da Assembléa Legislativa da mesma província em oi/03/1850. 
a criação das juntas de Higiene Pública (KODAMA et al., 20I2, p. 6I). Na Província da Bahia, por exemplo, um edifício foi destinado para abrigar os pacientes da febre amarela e uma junta de médicos foi designada pela presidência da província para tratálos. Nos primeiros meses da epidemia na Bahia, I.3Io estrangeiros faleceram da doença 5 .

Outros arranjos também foram feitos, como no caso do Rio de Janeiro, durante a pandemia de cólera, quando a Santa Casa de Misericórdia foi obrigada, por decreto, a preparar três enfermarias especiais em diferentes freguesias da cidade para receber os pacientes. Posteriormente à prestação do serviço de saúde e assistência à população, a Santa Casa encaminhava ao Tesouro Nacional as contas detalhadas dos custos com a contratação de médicos, enfermeiros, ajudantes, aluguel de casas, compra de medicamentos, alimentos e material de escritório visando ao ressarcimento pelo erário público (KODAMA et al., 20I2, p. 62).

Em se tratando do cólera-morbo, esta doença provocou graves efeitos sobre a saúde da população brasileira. Moléstia que atormentou a humanidade desde a Antiguidade, sobretudo na Índia, seu país de origem, o cólera ficou conhecido como “mal dos Ganges” (SANTOS, 2016, p. 343). A intensificação do comércio marítimo provocou sua disseminação para outros países e continentes. Durante todo o século XIX, com a ampliação das relações comerciais internacionais, fruto da expansão do sistema capitalista e da melhoria nos transportes, houve uma eclosão de ondas pandêmicas. Do foco originário da doença e de sua expansão inicial pelo continente asiático, o cólera se disseminou pelo mundo pelas rotas comerciais estabelecidas (ALMEIDA, 20II, p. IO6I). Sua primeira manifestação pandêmica começou no ano de I8I7 e perdurou até o ano de I823, atingindo fortemente a Rússia (BELTRÃO, 2007, p. I47; ALMEIDA, 20II, p. I06I). Ao alcançar a Europa na década de I830, o cólera se alastrou rapidamente vitimando uma quantidade expressiva de europeus, conforme relata Almeida (20II, p. IO6I):

Em I832 morreram 6.536 pessoas de cólera em Londres, vinte mil em Paris. Em toda a França, a doença fez mais de cem mil vítimas. Essa primeira vaga da epidemia chegou a Portugal em I833, mais precisamente ao Porto, a bordo do vapor London Marchant, com o

\footnotetext{
${ }^{5}$ FALLA que recitou o Presidente da Província da Bahia, Francisco Gonçalves Martins, n'Abertura da Assembléa Legislativa da mesma província em oi/03/I850.
} 


\section{C) GitistóróRICA}

general Solignac e duzentos soldados belgas vindos de Ostende para ajudar os liberais na guerra civil. Durante o cerco do Porto e depois, quando se espalhou pelo país, a epidemia de cólera acabou por causar mais de quarenta mil mortos, um número mais elevado do que o da própria guerra.

Pode-se perceber quão grave era o cólera, uma vez que na primeira onda epidêmica em Portugal, ainda nos anos I830, vitimara mais pessoas que a própria guerra civil, que durou de I832 a I834 e foi fruto da disputa entre monarquistas absolutistas e liberais constitucionalistas pelo poder (BIRMINGHAM, 20I5, p. I34). Em I849, a Europa vivenciou uma segunda onda epidêmica do cólera e, logo em seguida, uma terceira, que durou de I852 a I860. Esta última matou mais de um milhão de pessoas, sendo a Rússia o país mais afetado. Em Portugal, ela chegou em dezembro de I853, quando dois casos foram registrados no norte do país. Aos poucos o cólera se alastrou, amplificando a quantidade de mortes, sobretudo a partir de maio de I854, momento em que medidas de quarentena foram postas em prática para conter a disseminação da doença, corroborando a ideia de que esta é uma prática antiga para enfrentar epidemias (ALMEIDA, 20II).

De Portugal, o cólera alcançou o Brasil no ano de 1855 com a chegada da embarcação portuguesa Deffensor, que aportou na capital da Província do Grão-Pará, oriunda da cidade do Porto. Ela foi identificada pelas autoridades locais como a responsável por trazer o cólera para Belém e, consequentemente, para o Brasil (BELTRÃO, 2002, p. 24I). Da Província do Grão-Pará, ainda segundo Beltrão (2007, p. I48), o cólera se deslocou para a Bahia, chegando em terras baianas em junho de I855 para, em seguida, alcançar a capital do Império no mês de julho. Houve registros do cólera também nas Províncias de Sergipe, Alagoas, Pernambuco, Rio Grande do Norte, Amazonas, Maranhão e Espírito Santo. No Ceará, ao que parece, o cólera teria chegado um pouco mais tarde, entre os anos de I86I e I862 (BELTRÃO, 2007; KODAMA et al., 20I2).

O mundo vivenciou ao menos seis pandemias de cólera-morbo. A que atingiu a Bahia, o Grão-Pará, Pernambuco e o Rio de Janeiro foi a terceira. Segundo Beltrão (2007, p. 148), a quarta parece ter sido a mais catastrófica, com uma mortalidade mais elevada que as demais. A Índia chegou a 360 mil mortos, enquanto na Europa os números alcançaram 450 mil vítimas. No Brasil, a quarta onda pandêmica chegou no 
final dos anos I86o, atingindo o Rio Grande do Sul, Santa Catarina e Mato Grosso. Nesta última província, o cólera vitimou tanto, quanto a Guerra do Paraguai.

No Espírito Santo, por exemplo, o cólera chegou em novembro de I855 e vitimou, ao final da crise epidêmica, I.70o capixabas, de uma população total de 49.092 pessoas (FRANCO, 20I4, p. I24). Este montante de mortos representava, aproximadamente, $3,5 \%$ do contingente populacional da província. A maioria das vítimas, assim como ocorreu em outras partes do Brasil, era composta por pessoas pobres (FRANCO, 20I4, p. I27). Ainda segundo o autor, a doença se alastrou e contaminou também os indígenas que viviam na província:

Segundo o jornal Correio da Victoria, seu efeito foi devastador: “[...] os índios estavam morrendo as dúzias" e para complicar mais a situação, faltavam médicos, medicamentos e enfermarias para acolher tantos doentes. Em Santa Cruz, as primeiras notícias que se tem da cólera foi com a morte do soldado Antonio Pedro. Nessa localidade, as mortes estavam ocorrendo mais na região interiorana, como Caieiras Velhas, local onde moravam os habitantes remanescentes da aldeia dos tupiniquins que estavam morrendo em grande quantidade.

Beltrão (2002, p. 243) reforça a informação de que a maioria das vítimas do cólera eram pessoas pobres, independentemente de serem livres ou escravas. As péssimas condições de moradia e higiene, combinadas a uma alimentação pouco nutritiva contribuíam para uma incidência maior de doenças, e do cólera, em particular. Kodama e demais autores (2012) discordam dessa leitura e afirmam que a maioria das vítimas do cólera-morbo eram escravos ou libertos, embora a doença também atingisse a população pobre de uma maneira significativa. Ainda segundo estes autores, quem levou o cólera para o Rio de Janeiro foi um escravo oriundo da Província do Grão-Pará. Com o tempo, a doença se alastrou pela capital do Império, registrando altas taxas de mortalidade, sobretudo entre os meses de setembro e novembro de I855, período em que se verificou um pico de setenta a oitenta mortes por dia, totalizando, somente no mês de novembro, 2.30o óbitos. A partir de dezembro começaram a refluir os casos e as mortes por cólera. Os últimos registros ocorreram no mês de junho de I856 (KODAMA et al, 2012, p. 66).

O cólera foi a mais importante crise sanitária que o Brasil enfrentou no decurso do século XIX, vitimando um contingente significativo de pessoas que ainda precisa 
ser melhor dimensionado à luz das diversas fontes documentais dispersas em arquivos por todo o país. Igualmente importante é se debruçar sobre os efeitos econômicos, tanto da pandemia do cólera, quanto da epidemia da febre amarela, menos letal, mas também relevante pelos impactos que provocou no cotidiano da sociedade brasileira oitocentista.

Este artigo busca contribuir de alguma forma para uma compreensão melhor dos efeitos econômicos mais gerais, a partir de dois indicadores: o desempenho da balança comercial e as receitas e despesas do Império. A análise dos números da balança comercial permite observar os efeitos da crise sanitária sobre o setor externo da economia brasileira no período, por meio das relações mercantis entre o Brasil e as demais nações. Os números relativos às receitas e despesas do Império no período em tela permitem checar se houve uma queda expressiva na arrecadação tributária nos momentos mais graves da emergência sanitária e se pode observar um aumento das despesas para enfrentar a crise, o que ajuda na compreensão do impacto financeiro sobre a sociedade e no comportamento do governo imperial em termos de auxílio no enfrentamento a um momento tão dramático vivenciado no país.

Os dados sobre o desempenho da balança comercial podem ser observados na Tabela I logo abaixo. A baliza cronológica tem início no ano de I850, já sob os efeitos da epidemia de febre amarela, iniciada na primavera do ano anterior, e termina no ano de I856, quando os últimos casos da pandemia de cólera-morbo foram verificados na década de 1850 .

Tabela I. A balança comercial brasileira (1850-1856)

\begin{tabular}{|c|c|c|c|}
\hline Período & $\begin{array}{c}\text { Exportações } \\
\text { (a) }\end{array}$ & $\begin{array}{c}\text { Importações } \\
\text { (b) }\end{array}$ & $\begin{array}{l}\text { Corrente de comércio } \\
\qquad(\mathbf{a}+\mathbf{b})\end{array}$ \\
\hline$I 850-I 85 I$ & 67.788:00o\$ & 76.918:000\$ & I44.706:000\$ \\
\hline$I 85 I-I 852$ & 66.640:00o\$ & 92.860:000\$ & I59.500:000\$ \\
\hline$I 852-I 853$ & $73.645: 000 \$$ & $87.332: 000 \$$ & I60.977:000\$ \\
\hline I853- I854 & $76.843: 000 \$$ & $85.839: 000 \$$ & I62.682:000\$ \\
\hline I854-I855 & 90.699:000\$ & 85.171:000\$ & I75.870:000\$ \\
\hline I855-I856 & $94.432: 000 \$$ & 92.779:000\$ & I87.2II:000\$ \\
\hline I856 - I857 & II $4.547: 000 \$$ & I25.227:000\$ & 239.774:000\$ \\
\hline
\end{tabular}

Fonte: IBGE, I990. Tabela adaptada pelo autor. 


\section{C) HitcastórRICA}

A análise dos dados permite observar uma queda das exportações brasileiras de I,7\% no ano de I85I, acompanhada de uma subida expressiva das importações, de cerca de $20,7 \%$. Este movimento não parece ter relação com a epidemia de febre amarela, mas sim com a valorização cambial experimentada pela moeda brasileira, que atingiu 8 \$244 réis, segundo os cálculos do IBGE (I990, p. 568), o que representou a maior apreciação cambial na década de I850. Nos anos seguintes, o câmbio se desvalorizou um pouco e as exportações se recuperaram lentamente. Ademais, a leitura dos estudos sobre a febre amarela no Brasil nesta época evidencia que ela impactou o país de maneira assimétrica, com algumas províncias enfrentando uma situação mais dramática. Esta discrepância permite conjecturar que o desempenho pior de uma província, pode ter sido compensado pelo desempenho melhor de outra, resultando num impacto agregado menos substancial.

Para o caso do cólera, o país parece ter sido afetado de maneira mais homogênea e com efeitos mais expressivos, o que explica o desempenho mais contundente, como pode ser observado no crescimento substancial das vendas ao exterior no ano de I856. O câmbio permaneceu estável em relação ao ano anterior, em 8 \$II réis, mas as exportações recrudesceram 2I,3\%, enquanto as importações subiram $35 \%$, resultando numa corrente de comércio $28,1 \%$ maior do que no exercício de I855I856 (IBGE, I990, p. 568). Sem a influência do câmbio, dois fatores podem ter maior relação com o crescimento significativo do comércio exterior do Brasil neste ano, o primeiro seria a queda dos preços internacionais dos gêneros comumente mais importados no país, o que não há evidências na literatura. O segundo seria uma melhoria na renda doméstica, que parece ter uma relação mais forte com esse desempenho, porque coincide com o fim da pandemia do cólera-morbo no país. Um dado adicional corrobora essa interpretação: a Recebedoria de Rendas Internas da Província da Bahia apresentou uma arrecadação de 298:869\$896 réis no exercício de I856-I857, contra 256:419\$548 réis no exercício anterior, o que representa um acréscimo de aproximadamente $17 \%$ nas receitas, permitindo inferir um recrudescimento da economia e da geração de renda na província. Parece razoável expandir essa leitura para o restante do Império, uma vez que o cólera assolou grande parte das províncias e o fim da crise sanitária se deu no mesmo ano em todo os locais do país por onde o bacilo passou.

Os dados referentes às receitas e despesas do Império permitem chegar à conclusão semelhante para todo o território nacional, após as devastações provocadas 
pela epidemia de febre amarela e pela pandemia do cólera-morbo. A despeito do prolongamento dos surtos de febre amarela no país no decorrer dos anos, o ano de maior emergência sanitária foi o de 1850 , pois, como visto, ela chegou ao país na primavera de I849. No ano seguinte, em I85I, o país já saíra da crise sanitária e, justamente neste ano, as receitas do Império apontam uma recuperação de $15,3 \%$ sobre o exercício anterior. Desempenho mais robusto no intervalo em tela, na ordem de 27,2\%, só será encontrado no exercício de I856-I857, notadamente, o período em que o Brasil saiu da crise sanitária provocada pelo cólera-morbo.

Tabela 2. Receitas e despesas da União (1850-1856)

\begin{tabular}{c|c|c|c|c}
\hline Período & Receita & $\%$ & Despesa & Saldo \\
\hline I850 - I85I & $32.697: 000 \$$ & - & $33.225: 000 \$$ & $-528: 000 \$$ \\
\hline I85I - I852 & $37.713: 000 \$$ & $+\mathrm{I} 5,3$ & $42.755: 000 \$$ & $-5.042: 000 \$$ \\
\hline $\mathrm{I} 852-\mathrm{I} 853$ & $38.103: 000 \$$ & $+\mathrm{I}, 0$ & $3 \mathrm{I} .654: 000 \$$ & $+6.449: 000 \$$ \\
\hline $\mathrm{I} 853-\mathrm{I} 854$ & $34.5 \mathrm{I} 6: 000 \$$ & $-9,4$ & $36.234: 000 \$$ & $-\mathrm{I} .7 \mathrm{I} 8: 000 \$$ \\
\hline $\mathrm{I} 854-\mathrm{I} 855$ & $35.985: 000 \$$ & $+4,3$ & $38.740: 000 \$$ & $-2.755: 000 \$$ \\
\hline $\mathrm{I} 855-\mathrm{I} 856$ & $38.634: 000 \$$ & $+7,4$ & $40.243: 000 \$$ & $-\mathrm{I} .609: 000 \$$ \\
\hline $\mathrm{I} 856-\mathrm{I} 857$ & $49.156: 000 \$$ & $+27,2$ & $40.374: 000 \$$ & $+8.782: 000 \$$ \\
\hline
\end{tabular}

Fonte: IBGE, I990. Tabela adaptada pelo autor.

Embora as receitas da União oscilem no transcurso do intervalo cronológico em destaque na Tabela 2, cumpre observar que os dois exercícios de recuperação mais significativa foram, precisamente, os que sucederam aos anos mais contundentes de emergência sanitária. A não observância de um aumento das despesas durante esses anos mais expressivos de disseminação das enfermidades permite levantar a hipótese de que o Estado assumiu poucas responsabilidades no seu enfrentamento, convergindo com a leitura de que se praticava uma "medicina liberal" no país neste período, conforme trata Cerqueira (2015), traduzindo essa expressão no modelo de financiamento da saúde pública brasileira durante o oitocentos e início do século XX. Este modelo delegava maiores responsabilidades ao conjunto da sociedade no financiamento da assistência social, cabendo ao governo uma contribuição percentual menor no total dos recursos. Contudo, esperava-se um aumento substancial desse auxílio governamental no intervalo cronológico em tela, em função de se tratar de uma emergência sanitária dramática. Os números, entretanto, não revelam, a princípio, 
nenhuma elevação para o enfrentamento à crise epidêmica. De qualquer modo, outros estudos se fazem necessários para uma afirmação mais consistente sobre esse tema.

\section{Economia e crise sanitária nos anos I850 na Província da Bahia}

A febre amarela teria aparecido pela primeira vez na Bahia no ano de I686, nos quatro primeiros dias do mês de abril e recebeu o nome de "bicha" pela voracidade e rapidez de seu alastramento. O número de doentes chegou a $25 \mathrm{mil}$, sendo um total de 900 vítimas fatais (FRANCO, I969, p. 23). Após essa crise sanitária, o mal amarílico foi relegado a segundo plano por mais de um século por ter deixado de se apresentar de forma epidêmica (FRANCO, 1969, p. 25).

Seu retorno ocorreu no dia 30 de setembro do ano de I849, quando um navio norte-americano, chamado Brasil, oriundo de Nova Orleans, onde a febre amarela estava fortemente disseminada, aportou em águas baianas ${ }^{6}$. Começava assim uma nova epidemia de febre amarela que, segundo David (1993, p. 29), vitimou 2 mil pessoas em toda a província. Tavares (2000, p. 273), por sua vez, apresentou um número maior de vítimas, cerca de três mil. Somente no primeiro ano, mais de cem mil pessoas teriam sido acometidas pela febre amarela e cerca de mil baianos teriam falecido vítimas da doença. Além deles, vários estrangeiros também morreram do mal amarílico, dentre eles, o cônsul norte-americano Thomaz Turner e o negociante inglês G. S. Sanville, capitão do brigue que trouxe a epidemia para a $\mathrm{Bahia}^{7}$, conforme relatou o Presidente da Província da Bahia, Francisco Gonçalves Martins ${ }^{8}$ :

[...] por quanto, podendo-se com firmesa dizer que nesta Cidade e subúrbio soffrerão a febre mais de Ioo mil pessoas Nacionaes, também posso asseverar que destas não morrerão mais de mil entre escravos e livres, resistindo assim á violencia do mal a admirável bondade do nosso clima, que apesar de ser na Estação de que trato o mais irregular que tenho presenciado, superou sua bondade esta mesma irregularidade, e as mil causas que nos cercão prejudiciais á saude publica.

\footnotetext{
${ }^{6}$ FALLA que recitou o Presidente da Província da Bahia, Francisco Gonçalves Martins, n’Abertura da Assembléa Legislativa da mesma província em or/03/1850.

7 Idem.

${ }^{8}$ Ibidem.
} 


\section{C) GitcastóRICA}

Estes números são imprecisos, pois a contabilização de infectados e mortos nas falas, mensagens e relatórios dos presidentes da Província da Bahia utiliza intervalos temporais diferentes, o que aumenta o risco de sobreposição de casos e nem sempre os dados estão organizados. Alguns relatórios detalham melhor os números, enquanto outros os apresentam de forma generalizada. De qualquer modo, a afirmação do Presidente da Província de que mais de roo mil nacionais teriam sido infectados pela febre amarela, possivelmente não deve estar muito distante do número real, uma vez que existe uma maior possibilidade de disseminação, quando um vírus novo alcança uma população. O número de casos tende a diminuir com o tempo e o aumento do percentual de acometidos pelo patógeno no conjunto de uma sociedade.

O número de mortos, por sua vez, tende a ser mais preciso nos documentos investigados, embora, provavelmente, seja inferior ao quantitativo total de vítimas da febre amarela. A soma simples dos dados coletados das falas, mensagens e relatórios dos presidentes da Província da Bahia entre 1850 e $1857^{9}$ totalizou I.740 pessoas falecidas, montante que se aproxima do relatado por David (1993, p. 29). Na fala do Presidente Francisco Gonçalves Martins, já citada anteriormente, consta uma tabela com o número de vítimas fatais da febre amarela para o período entre or de novembro de 1849 e 28 de fevereiro de I850. O total foi de I.3IO pessoas, sendo IOI escravos e os demais livres, entre brasileiros e estrangeiros ${ }^{10}$. Este montante representa, aproximadamente, $75 \%$ do total de mortes entre i849 e i856. O percentual de escravos que faleceram da febre amarela neste documento é de 7,7\%. Infelizmente, nos demais documentos, os dados não foram apresentados de maneira tão detalhada.

A epidemia de febre amarela se prolongou por vários anos sob a forma de surtos, e esse prolongamento terminou por somar seus efeitos aos danos perversos provocados pela chegada do cólera-morbo e sua rápida e mortal disseminação pela população baiana. De acordo com Tavares (2000, p. 273), dois anos após a chegada do mal amarílico, um novo surto ocorreu, vitimando mais baianos, porém sem informar o quantitativo de mortos. David (1993, p. 29-30), seguiu na mesma linha, afirmando que a febre amarela retornou, anualmente, na forma de surtos, tornando-se uma doença endêmica. As falas, mensagens e relatórios pesquisados corroboram essa leitura

\footnotetext{
9 As falas, mensagens e relatórios utilizados na pesquisa são datados de I850 a I857, logo, abordam o período entre I849 e I856, porém, na fala de I857, o Presidente da Província menciona números da febre amarela nos primeiros meses de $\mathbf{1 8 5 7}$. Por esta razão, este ano foi incluído na baliza cronológica.

Io FALLA que recitou o Presidente da Província da Bahia, Francisco Gonçalves Martins, n’Abertura da Assembléa Legislativa da mesma província em oi/03/I850.
} 
relatando que brasileiros e estrangeiros continuaram sendo vítimas, em número bem menor, pelo menos até o ano de I857, oito anos após o vírus chegar à Bahia.

O governo imperial e a presidência da Província da Bahia já demonstravam preocupação com o cólera-morbo, pelo menos três anos antes da sua chegada ao Brasil, e buscavam tomar as primeiras providências para tentar evitar sua disseminação no país e em terras baianas. O Presidente da Província da Bahia, João Maurício Wanderley, em discurso ocorrido no dia oI de março de $1853^{\mathrm{II}}$ trata desse tema:

\begin{abstract}
Apparecendo receio de que o cholera-morbus podesse invadir o nosso paiz pela rapidez das communicações que ora temos com a Europa, determinou o Governo Imperial que fosse consultada a comissão extraordinária, creada por aviso de 26 de Julho do anno passado, sobre os meios preventivos de que se devera lançar mao para preservar-nos deste cruel mal, e dos que deviam ser empregados no caso de termos a desgraça de ser por eles atacados. Reuni imediatamente a dita comissão e sinto dizer-vos que tendo decorrido mais de 2 mezes, não apresentou ella ainda seu parecer, que Deos permitta não seja necessario.
\end{abstract}

Cerca de um ano antes da chegada do cólera-morbo à Bahia, o Presidente da Província João Maurício Wanderley relatava a adoção de algumas medidas de precaução que estavam sendo tomadas, como a determinação de um local para a quarentena dos estrangeiros que chegassem portando a moléstia e a escolha da baía de Morro de São Paulo, distante de Salvador cerca de 64 quilômetros por mar, para a quarentena das embarcações. O local que abrigaria os pacientes infectados pelo cólera já estava passando por uma reforma para acomodá-los. O presidente defendia, também, a intensificação do asseio das ruas da cidade e das praias para diminuir o risco de contágio e disseminação da doença. Reconhecia apenas as dificuldades financeiras para ampliar as medidas de higienização ${ }^{\mathrm{I} 2}$.

Por fim, no mês de julho do ano de I855, o cólera-morbo desembarcou na cidade do Salvador, trazido por uma embarcação que viera de Belém do Pará, onde vitimara

\footnotetext{
II FALLA que recitou o Presidente da Província da Bahia, João Maurício Wanderley, n'Abertura da Assembléa Legislativa da mesma província em oi/03/1853.

${ }^{12}$ FALLA que recitou o Presidente da Província da Bahia, João Maurício Wanderley, n’Abertura da Assembléa Legislativa da mesma província em 0I/03/I855.
} 
muitas pessoas. A epidemia durou nove meses, registrando seus últimos casos no mês de abril do ano de I856. Na sua passagem por terras baianas, ela se revelou extremamente mortífera, vitimando, aproximadamente, 36 mil pessoas (DAVID, I993, p. 9)! De acordo com Kodama et al. (2012, p. 75), a pandemia de cólera teria sido mais agressiva na Bahia, se comparando com os resultados do Rio de Janeiro, Pará e Pernambuco. O historiador baiano Luiz Henrique Dias Tavares (2000, p. 273) parece corroborar essa interpretação:

Em I855, o cólera desembarcou na cidade do Salvador de um navio chegado de Belém do Pará. Rapidamente alcançou Santo Amaro, Cachoeira e Nazaré, cidades altamente populosas (na proporção da época). Maior centro da produção de açúcar da Bahia, Santo Amaro ficou com suas plantações e engenhos abandonados. Morreram milhares de escravos. A cidade de Santo Amaro tomou aspecto de cemitério. Não havia médicos, não existiam hospitais, os mortos ficavam insepultos.

O cólera foi uma doença devastadora por onde passou. Sua contaminação ocorre por meio do contato com o bacilo Vibrio cholerae, presente em bebidas ou comidas contaminadas. No organismo humano, o bacilo se dissemina rapidamente provocando vômitos e diarreia, levando em poucas horas a um quadro severo de desidratação. A doença também se espalha por meio dos excrementos dos portadores. Locais com condições sanitárias precárias são foco importante de disseminação da doença. A melhoria das condições sanitárias e o maior conhecimento acerca de sua transmissão reduziram drasticamente sua ocorrência e o tratamento com antibióticos também possibilitou um enorme avanço na redução da mortalidade.

Os impactos da pandemia sobre a economia provincial e o comércio, em particular, foram igualmente devastadores. Com o advento do cólera, os mercadores passaram a evitar a cidade do Salvador, reduzindo dramaticamente seu abastecimento. A redução na oferta de alimentos fez os preços se elevarem de maneira substancial, dificultando a sobrevivência, sobretudo da população pobre soteropolitana. Segundo David (1993, p. II9), o cônsul inglês John Morgan relatava que os preços de gêneros de subsistência haviam aumentado 50\% em seis meses de pandemia, os aluguéis, $200 \%$ em cerca de um ano, enquanto os empregados domésticos elevaram o preço dos seus serviços em I0o\%. A despeito da possibilidade do cônsul estar exagerando em seu 
relato, conforme aventa David, há depoimentos adicionais que reforçam a tese de que a capital da Província da Bahia atravessava um período de elevada inflação, que comprometia a subsistência dos mais pobres num momento de temor pela disseminação do cólera. David (1993, p. II8) cita o relato do dr. Rodrigues Seixas, que assim se referiu à elevação dos preços no mercado soteropolitano:

As famílias dos artistas privadas do lucro, os pobres sem recurso, procurando os gêneros de primeira necessidade, ou não os acha no mercado, ou os encontra por preço extraordinário: do que resulta que a alimentação pública no tempo da crise epidêmica, é privilégio do rico.

Ao desabastecimento e a carestia vivenciados no mercado doméstico, se somaram os recuos no desempenho do comércio exterior baiano. Os dados da balança comercial da Província da Bahia durante o intervalo cronológico que envolve as duas emergências sanitárias dos anos I850, evidenciam que ambas contribuíram para uma deterioração no desempenho do comércio exterior baiano no período em tela. É interessante notar como, tanto as exportações, quanto as importações da província, assim como, consequentemente, sua corrente de comércio, refletem os efeitos expressivos da crise sanitária sobre essas variáveis econômicas. A análise desses dados não permite afirmar, naturalmente, que o desempenho inferior da balança comercial na baliza cronológica em tela se deu, exclusivamente, devido aos impactos das duas doenças sobre o conjunto da atividade econômica provincial. Porém, parece evidente que a crise sanitária exerceu importante influência sobre o desempenho geral da balança comercial, uma vez que os resultados são, perceptivelmente, inferiores durante a sua vigência, conforme pode ser observado na Tabela 3 abaixo:

Tabela 3. Balança comercial da Província da Bahia (I850 - I856)

\begin{tabular}{c|c|c|c}
\hline Exercício & $\begin{array}{c}\text { Exportações } \\
(\mathbf{a})\end{array}$ & $\begin{array}{c}\text { Importações } \\
(\mathbf{b})\end{array}$ & $\begin{array}{c}\text { Corrente de Comércio } \\
(\mathbf{a}+\mathbf{b})\end{array}$ \\
\hline $\mathrm{I} 850-\mathrm{I} 85 \mathrm{I}$ & $9.854: 407 \$$ & n.d. & - \\
\hline $\mathrm{I} 85 \mathrm{I}-\mathrm{I} 852$ & $8.660: 997 \$$ & $\mathrm{I} 3 . \mathrm{I02}: 553 \$$ & $21.763: 550 \$$ \\
\hline $\mathrm{I} 852-\mathrm{I} 853$ & $\mathrm{I}$ \$.656:745\$ & $\mathrm{I} 4.243: 229 \$$ & $24.899: 974 \$$ \\
\hline $\mathrm{I} 853-\mathrm{I} 854$ & $\mathrm{I} 5.431: 105 \$$ & $\mathrm{I} 3.738: 853 \$$ & $24.169: 958 \$$ \\
\hline
\end{tabular}




\begin{tabular}{l} 
Crética \\
\hline \\
\hline $\mathrm{I} 854-\mathrm{I} 855$
\end{tabular}

Fonte: BAHIA, I978c.

Assim como aconteceu com as exportações brasileiras no período, as vendas ao exterior da Província da Bahia declinaram durante o exercício de I85I-I852, porém, de maneira bem mais expressiva, com queda de $12,1 \%$. Como mencionado, a maior valorização cambial no intervalo de uma década, parece ser, claramente, o principal fator para redução tão substancial. Contudo, a discrepância significativa entre o desempenho das exportações baianas em comparação com o quadro nacional permite inferir que a epidemia de febre amarela, mais intensa na província, contribuiu fortemente para a acentuação desse declínio. As palavras do Presidente da Província, Francisco Gonçalves Martins reforçam essa interpretação ${ }^{13}$ :

A população quasi toda tem adoecido; os indivíduos, expondo-se pouco ao trabalho já antes mesmo de serem affectados, como se lhes aconselhava, durante a molestia e convalescença nada fazião, e muitos dias depois seu trabalho era frouxo e pouco vantajoso. $\mathrm{O}$ resultado pois de tanta inacção deve muito influir nos produtos do paiz. O commercio tem igualmente recebido grandes prejuízos; o mercado esteve quasi paralisado; muitos navios se achavão sem tripulação, e alguns à chegada do porto, sabendo o que se passava neste, retiravão; outros não esperavão completar sua carga, e muitos deixarão de sahir á falta de marinhagem, cuja procura se tornou diffícil e dispendiosa, resultando d'ahi a subida dos fretes; o que tudo se converte em prejuízo de nossa lavoura.

Os impactos econômicos da epidemia de febre amarela estavam sendo sentidos pela província, com reflexos no desempenho do comércio exterior, pelo aumento nos valores dos fretes e causando prejuízos à lavoura. A queda bem menos expressiva das exportações nacionais pode ser traduzida, conforme já mencionado, pelo impacto assimétrico da epidemia de febre amarela no território brasileiro. Outro fator reforça

${ }^{13}$ FALLA que recitou o Presidente da Província da Bahia, Francisco Gonçalves Martins, n'Abertura da Assembléa Legislativa da mesma província em oi/03/1850. 
essa leitura: a recuperação mais substancial das exportações baianas no exercício seguinte, entre I852 e I853, de cerca de $23 \%$, enquanto o crescimento das exportações nacionais foi de, aproximadamente, I0,5\%. A desvalorização cambial teve um papel importante neste desempenho, mas parece evidente que o fim da emergência sanitária contribuiu de maneira significativa, uma vez que, como já abordado, a febre amarela permaneceu como surtos endêmicos, porém, sem causar a quantidade de mortes como no período entre os anos de I849 e I850.

Por fim, do mesmo modo que pôde ser verificado para o quadro geral da balança comercial do Brasil no período, a recuperação das exportações baianas, assim como das importações e, consequentemente, da corrente de comércio, no primeiro exercício pós-pandemia de cólera-morbo somente corrobora a interpretação de que esta provocou importantes estragos nas relações mercantis internacionais da Província da Bahia. Um cálculo simples permite chegar a um crescimento de 38,9\% nas receitas de exportação no exercício de I856-I857, em relação ao intervalo anterior. Para a mesma baliza cronológica, as importações recrudesceram $49 \%$, resultando numa corrente de comércio 44,I\% maior do que entre I855 e I856. Conforme visto na análise da balança comercial brasileira neste período, o câmbio permaneceu estável e não foi documentada nenhuma queda substancial dos preços internacionais ou domésticos nestes anos. Este conjunto de fatores, permite estabelecer uma relação de causalidade entre a recuperação da economia baiana, após o fim dos anos epidêmicos, com o incremento substancial nas relações comerciais exteriores. Esta interpretação é atestada pelo relato do cônsul inglês John Morgan no ano de i857. De acordo com David (1993, p. I32), o cônsul afirmou que o ano de I856 seria lembrado como um dos mais satisfatórios para o comércio exterior baiano e que a Inglaterra obteve um lucro fabuloso com o incremento das importações baianas no período.

Os reflexos do período em que duas crises sanitárias atingiram a Província da Bahia, também podem ser observados na análise dos dados sobre suas receitas ${ }^{\mathrm{I}}$. É de se esperar que um conjunto variado de fatores internos e externos influenciem na arrecadação tributária, porém parece evidente o comportamento atípico das rendas provinciais nos exercícios imediatamente posteriores ao fim da epidemia de febre

\footnotetext{
${ }^{\text {I4 }}$ Os dados sobre as receitas da Província da Bahia estavam bem detalhados e organizados no documento referenciado como fonte da Tabela 4. Porém, em nenhum dos documentos pesquisados foram encontrados dados organizados e detalhados para as despesas. As informações são confusas e relatam números muito díspares dos apresentados nesta tabela. Por prudência, os dados de despesa anualizados não foram inseridos para evitar uma leitura equivocada sobre o estado financeiro da Província da Bahia.
} 
amarela, I85I-I852, e do cólera-morbo, I856-I857. Como pode ser constatado nos números apresentados na Tabela 4, o desempenho no exercício de I85I-I852 foi 19,6\% melhor do que no exercício anterior, quando a economia baiana estava sob a emergência sanitária provocada pelo mal amarílico. De igual modo, o crescimento expressivo das receitas provinciais no exercício entre 1856 e I857, de aproximadamente $44,9 \%$, quando comparado com o intervalo anterior, momento em que os efeitos da pandemia de cólera-morbo eram mais severos, permitem afirmar que existe uma relação direta entre os desdobramentos da crise sanitária e os resultados econômicos mais danosos sobre a estrutura produtiva, comercial e financeira doméstica.

Tabela 4. Receitas da Província da Bahia (I850 - I856)

\begin{tabular}{c|c|c}
\hline Exercício & Receitas & $\%$ \\
\hline $\mathrm{I} 850-\mathrm{I} 85 \mathrm{I}$ & $4.972: 259 \$ 5 \mathrm{I} 5$ & - \\
\hline $\mathrm{I} 85 \mathrm{I}-\mathrm{I} 852$ & $5.946: \mathrm{I} 42 \$ 089$ & $+\mathrm{I} 9,6$ \\
\hline $\mathrm{I} 852-\mathrm{I} 853$ & $5.362: 932 \$ 4 \mathrm{I} 3$ & $-9,8 \%$ \\
\hline $\mathrm{I} 853-\mathrm{I} 854$ & $4.913: 995 \$ \mathrm{I} 22$ & $-8,4 \%$ \\
\hline $\mathrm{I} 854-\mathrm{I} 855$ & $4.969: 60 \mathrm{I} \$ 85 \mathrm{I}$ & $+\mathrm{I}, \mathrm{I}$ \\
\hline $\mathrm{I} 855-\mathrm{I} 856$ & $5.354: 2 \mathrm{I} 2 \$ 396$ & $+7,7$ \\
\hline $\mathrm{I} 856-\mathrm{I} 857$ & $7.760: 8 \mathrm{IO} \$ 985$ & $+44,9$
\end{tabular}

Fonte: APEB. FALLA que recitou o Presidente da Província da Bahia, João Lins Vieira Cansansão e Sinimbú, n’Abertura da Assembléa Legislativa da mesma província em oi/o9/1857.

Informações contidas em dois documentos corroboram essa interpretação. A Tesouraria da Província da Bahia relatou, em I850, uma previsão de queda na arrecadação tributária entre 20:000\$ a 25:000\$ em função da epidemia de febre amarela. Os trapiches, igualmente, receberam uma carga muito menor de mercadorias, quando comparada com o ano de I848. Neste, entraram nos trapiches da província 39.045 caixas, enquanto no segundo semestre de I849, este número caiu para I4.980, o que não representa nem a metade do ano anterior. Quanto à saída de caixas com produtos, em I848 este quantitativo foi de 65.439, no semestre em análise, contudo, esta soma alcançou I8.537 caixas $^{15}$, o que representa $28,3 \%$ do quantum de exportações do ano anterior. Já o presidente da Província da Bahia, Alvaro Tibério Moncorvo e

${ }^{15}$ FALLA que recitou o Presidente da Província da Bahia, Francisco Gonçalves Martins, n'Abertura da Assembléa Legislativa da mesma província em oi/03/1850. 


\section{C) HISTT́T́RICA}

$\mathrm{Lima}^{16}$, apontou, no ano de I856, a pandemia de cólera-morbo como uma das principais razões para a queda na arrecadação provincial, conforme segue:

A receita effectiva desse anno foi de I,I06:642\$669, inclusive a do Celleiro Publico na importancia de II:936\$005 rs. De Janeiro [...] á 26 de Fevereiro do anno corrente arrecadou-se por conta desse exercicio 45:352\$574 rs., havendo razão para esperar que até o fim do semestre addicional se arrecade ainda cerca de Io:0oo $\$$ rs., vindo portanto toda a renda do exercício a montar á I,I6I:995\$243 rs., e excedendo assim a do anterior em cerca de 20:00o\$ rs. Pode-se com segurança presumir que esse crescimento seria muito maior se a Provincia houvera escapado á devastação da cruel epidemia, que infelizmente a invadio no fim de Julho do anno passado, e que, amortecendo a arrecadação da Mesa de Rendas Provinciaes, suspendeu inteiramente a das Collectorias de Cachoeira e Santo Amaro, não sendo as outras indiferentes á esse estremecimento geral.

Embora os dados sobre as despesas provinciais no intervalo cronológico em análise não tenham gozado da mesma organização na compilação das informações, frequentemente apresentadas de maneira confusa e parcial, um documento especificamente chamou a atenção por apresentar as despesas da Província da Bahia com a pandemia de cólera-morbo entre 5 de junho de I 855 e 28 de abril de $1856^{17}$. Neste documento, constam informações interessantes como os gastos do governo com alimentos para amenizar a situação, possivelmente famélica, de parte da população mais pobre, aquisição de medicamentos, custos com postos sanitários, lazaretos, remuneração dos profissionais que atuaram no enfrentamento da pandemia, ambulâncias, padiolas, condução e sepultamento dos mortos, dentre outros. Na Tabela 5 os dados foram compilados e organizados de modo a se perceber a participação de cada item na composição dos gastos públicos.

Tabela 5. Gastos do governo da Província da Bahia na pandemia do cólera-morbo $(05 / 06 / 1855-28 / 04 / 1856)$

\footnotetext{
${ }^{16}$ FALLA que recitou o Presidente da Província da Bahia, Alvaro Tibério Moncorvo e Lima, n’Abertura da Assembléa Legislativa da mesma província em I4/05/1856.

${ }^{17}$ Idem.
} 


\begin{tabular}{|c|c|c|}
\hline Destinação & Montante & $\%$ \\
\hline Lazaretos e postos sanitários & $27: 540 \$ 175$ & 6,2 \\
\hline Comissão de Higiene & $700 \$ 560$ & 0,2 \\
\hline Comissariado do Governo & I7:994\$IO3 & $4, \mathrm{I}$ \\
\hline Gêneros alimentícios & $25: 66 I \$ 2 I 4$ & 5,8 \\
\hline Remuneração dos Profissionais de saúde & $47: 573 \$ 893$ & $\mathrm{IO}, 8$ \\
\hline Remuneração de outros profissionais & $48: 626 \$ 666$ & II,O \\
\hline Medicamentos & $\mathrm{I} 3: 740 \$ 582$ & $3, \mathrm{I}$ \\
\hline Ambulâncias e padiolas & $7: 406 \$ 020$ & $\mathrm{I}, 7$ \\
\hline Transporte e sepultamentos & $6: 999 \$ 800$ & $\mathrm{I}, 6$ \\
\hline Transportes em geral & I8:133\$620 & $4, \mathrm{I}$ \\
\hline Outros socorros aos pobres & $6: 372 \$ 515$ & $\mathrm{I}, 4$ \\
\hline Desinfecção & $439 \$ 184$ & O,I \\
\hline Fornecedores diversos e comissariado & I4I:832\$276 & $32, \mathrm{I}$ \\
\hline Suprimentos para outras Províncias & $6 \mathrm{I}: 858 \$ 6 \mathrm{I} 4$ & $\mathrm{I} 4, \mathrm{O}$ \\
\hline Despesas diversas & I6:789\$I77 & 3,8 \\
\hline Total & $44 \mathrm{I}: 668 \$ 396$ & 100,0 \\
\hline
\end{tabular}

Fonte: FALLA que recitou o Presidente da Província da Bahia, Alvaro Tibério Moncorvo e Lima, n’Abertura da Assembléa Legislativa da mesma província em I4/05/1856. Tabela adaptada pelo autor.

A partir da observação dos dados presentes na tabela acima, é fácil observar que a maior despesa foi com o pagamento aos mais diversos fornecedores e ao comissariado encarregado de estabelecer essas relações. Chama a atenção a despesa com suprimentos a outras províncias, como Sergipe, Alagoas, Pernambuco, Paraíba, Rio Grande do Norte e, até o Rio de Janeiro que, representaram I4\% do montante despendido. A remuneração dos profissionais de saúde (médicos, farmacêuticos e enfermeiros), bem como outros profissionais (acadêmicos, policiais, marinheiros, capelães, etc.) representam $2 \mathrm{I}, 8 \%$ do total. $\mathrm{O}$ auxílio aos pobres pode ser compilado pelas despesas com gêneros alimentícios e com o socorro direto que, somados, significam $7,2 \%$ dos gastos totais. Se o montante de 44I:668\$396 representar o total das despesas governamentais com a pandemia de cólera morbo entre I855 e I856, o auxílio aos mais carentes ficou com uma parte muito pequena do total, possivelmente atenuando muito pouco o quadro social e econômico enfrentado pela emergência sanitária. 


\section{C) GitistóñICA}

Conforme mencionado anteriormente, nesta época, o Brasil adotava um modelo de "medicina liberal" baseado na compreensão de que cabia à sociedade a responsabilidade com a assistência social. Somente para se ter uma ideia, as santas casas tinham como suas principais fontes de financiamento, aluguéis de imóveis e loterias, estas últimas, fruto de concessão dos governos provinciais. No caso da Santa Casa de Cachoeira, por exemplo, estas duas rubricas, somadas, representaram 40,56\% do montante total auferido entre os anos de I853 e I86I. Quando se acrescentam as esmolas, caixinhas e doações, o percentual alcança 5I,49\% das receitas totais no período citado. As receitas oriundas de repasses governamentais representaram apenas $25,80 \%$ do montante total, neste mesmo intervalo temporal, que, por sinal, abrange o período da crise sanitária (CERQUEIRA, 2015, p. 199-200). A despeito do modelo "liberal", esperava-se um aporte maior de recursos do governo devido ao momento excepcional e dramático imposto pelas moléstias disseminadas em solo baiano. A princípio, isto não parece ter ocorrido, ao menos na medida das reais necessidades da população.

Como conclusão, não há dúvidas de que mais estudos precisam ser feitos sobre os desdobramentos econômicos da epidemia de febre amarela e da pandemia de cólera-morbo, tanto para a Província da Bahia, quanto para as demais províncias que foram afetadas por essas crises sanitárias num intervalo de tempo tão curto. De qualquer modo, o rol de despesas apresentado na última tabela permite afirmar que o Estado poderia ter feito um esforço financeiro maior para mitigar o sofrimento imposto pela pandemia de cólera. A despeito dos estudos importantes já realizados e mencionados neste trabalho, novas pesquisas iluminarão ainda mais este tema, infelizmente, tão atual, a fim de que se possa compreender melhor os impactos multifacetados das epidemias sobre as populações no imenso território brasileiro.

\section{Considerações finais}

A epidemia de febre amarela e a pandemia do cólera-morbo atingiram o Brasil num intervalo de poucos anos, se constituindo em uma crise sanitária prolongada, a depender da região afetada. As dimensões continentais do território brasileiro, porém, contribuíram para que os efeitos das moléstias fossem assimétricos nas províncias, levando algumas a vivenciarem rebatimentos muito mais severos do que outras. Esse quadro, possivelmente, se refletiu no desempenho da balança comercial do país e na análise de suas receitas e despesas que, embora evidenciando os efeitos da emergência sanitária, apresentaram resultados menos expressivos do que a Província da Bahia, por 
exemplo, fato que pode ser explicado pelos efeitos menos adversos das doenças em algumas províncias, enquanto outras, como no caso baiano, os impactos foram mais significativos.

A historiografia aponta que a Província da Bahia foi uma das mais atingidas, tanto pela febre amarela, quanto pelo cólera-morbo, o que se refletiu nos números elevados de acometidos e de vítimas fatais. Este cenário se traduziu nos impactos econômicos mais substanciais sobre as relações de comércio exterior e a arrecadação da Tesouraria Provincial. Conforme visto, enquanto as exportações nacionais declinaram I,7\% no ano de I85I, na Província da Bahia a queda foi de I2,I\%. Quando se observa os percentuais referentes às exportações para 1856, a recuperação nacional foi de $21,3 \%$, ao mesmo tempo em que a retomada baiana alcançou 38,9\%. Ao se debruçar sobre o comportamento das receitas do Império, verificou-se uma recuperação de I5,3\% em I85I e de 27,2\% em I856. A arrecadação da Província da Bahia, mais uma vez, apresentou um resultado mais expressivo, com crescimento de 19,6\% em I85I e de 44,9\% em I856. Estes dados sugerem uma correlação entre os efeitos econômicos mais intensos e o fato de que as crises sanitárias foram mais severas em terras baianas.

As despesas com a pandemia do cólera-morbo, em particular, trouxeram uma evidência de que os gastos do governo no socorro direto aos mais vulneráveis representou um percentual muito pouco expressivo face ao total de despesas da Província da Bahia com a emergência sanitária, o que pode ter tido um efeito mínimo na tentativa de amenizar o dramático quadro econômico e social experimentado pela sociedade baiana naquele momento. Mais estudos precisam ser feitos, contudo, para se averiguar melhor o papel do Estado no socorro aos mais vulneráveis e ao conjunto da sociedade em geral. Por fim, parece importante que surjam mais pesquisas sobre as crises sanitárias e seus desdobramentos multifacetados, tanto para o caso da Bahia, quanto para as demais províncias do Império, de modo a permitir uma compreensão melhor dos diversos rebatimentos que eventos dessa dimensão produzem no cotidiano das populações e que transcendem as questões mais diretas relacionadas à saúde.

\section{Referências}

AEB. Previsão da balança comercial para 202I. Associação de Comércio Exterior do Brasil. Disponível em: http://aeb.org.br/previsao-da-balanca-comercial-202I/ Acesso em: 22 jan 2O2I. 
ALMEIDA, Maria Antónia Pires de. A epidemia de cólera de I853-1856 na imprensa portuguesa. Rio de Janeiro: História, Ciências, Saúde - Manguinhos, v. I8, n. 4, out. dez. de 20II. p. I057-I07I.

ATHAYDE, Johildo Lopes de. Salvador e a grande epidemia de 1855. Salvador: Publicações do Centro de Estudos Baianos (CEB-UFBA), n. II3, I985.

BAHIA. Secretaria de Planejamento, Ciência e Tecnologia. A Inserção da Bahia na Evolução Nacional - I ${ }^{\text {a }}$ Etapa: I850-I889 - Atividades Produtivas. Salvador: Fund. Centro de Pesquisas e Estudos - CPE, 1978a.

. A Inserção da Bahia na Evolução Nacional - I $^{\text {a }}$ Etapa: I850-I889 - Atividades Não-Produtivas. Salvador: Fund. Centro de Pesquisas e Estudos - CPE, 1978b.

A Inserção da Bahia na Evolução Nacional - I'a Etapa: I850-I889 - Anexo Estatístico. Salvador: Fund. Centro de Pesquisas e Estudos - CPE, I978c.

BCB. Focus - Relatório de mercado. Brasília: Banco Central do Brasil (BCB), II/I2/2020. Disponível em: https://www.bcb.gov.br/publicacoes/focus/III22020 Acesso em: 22 jan. 2O2I.

BELTRÃO, Jane Felipe. Autoridade médica e divulgação científica no Grão-Pará flagelado pelo cólera: século XIX. Porto Alegre: Horizontes Antropológicos, ano 8, n. I7, junho de 2002. p. 239-252.

. Memórias da cólera no Pará (I855 e I99I): tragédias se repetem? Rio de Janeiro: História, Ciências, Saúde - Manguinhos, v. I4, suplemento, dezembro de 2007. p. I45-I67.

BENCHIMOL, Jaime. Dos micróbios aos mosquitos: febre amarela e revolução pasteuriana no Brasil. Rio de Janeiro: Editora Fiocruz, I999.

BIRMINGHAM, David. História concisa de Portugal. São Paulo: EDIPRO, 2015. CERQUEIRA, João Batista de. Caridade, política e saúde: o Hospital São João de Deus e a Santa Casa de Misericórdia de Cachoeira, Bahia (I756 a I872). 2015. $277 \mathrm{f}$. Tese (Doutorado em Ensino, Filosofia e História das Ciências). Programa de Pós-Graduação em Ensino, Filosofia e História das Ciências, Universidade Federal da Bahia e Universidade Estadual de Feira de Santana, Salvador/Bahia, 2015.

CHALHOUB, Sidney. Cidade febril: cortiços e epidemias na corte Imperial. São Paulo: Companhia das Letras, 2004.

DAVID, Onildo Reis. O inimigo invisível: a epidemia do cólera na Bahia em I855-56. Salvador: UFBA (dissertação de mestrado), 1993. I75 f. 
FOLHA DE SÃO PAULO. Veja o desempenho do PIB de vários países em 2020 e no $4^{.0}$ trimestre. Folha de São Paulo, 03/03/202I. Disponível em: https://wwwI.folha.uol.com.br/mercado/202I/03/veja-o-desempenho-do-pib-devarios-paises-em-2020-e-no-40-trimestre.shtml. Acesso em: I9 mar. 202I.

FRANCO, Odair. História da febre amarela no Brasil. Rio de Janeiro: Imprensa Nacional, 1969.

FRANCO, Sebastião Pimentel. Pânico e terror: a presença da cólera na Província do Espírito Santo (I855-I856). Guarulhos: Almanack, n. O7, I ${ }^{\circ}$ semestre de 20I4. p. II7-I36. FREITAS, Ricardo Cabral de. Ardentes trópicos: febres e saúde pública no Brasil joanino. Rio de Janeiro: História, Ciências, Saúde - Manguinhos, v. 27, n. 3, jul.-set., 2020. p. 723-740.

GAITORS, Beau DJ. Comércio, conflito e contaminação: febre amarela no início da independência em Vera Cruz no imaginário dos Estados Unidos, I82I-I848. Rio de Janeiro: História, Ciências, Saúde - Manguinhos, v.25, n. 3, jul.-set., 2018.

IBGE. Estatísticas históricas do Brasil. 2 ed., Rio de Janeiro: IBGE, I990.

KODAMA, Kaori et al. Mortalidade escrava durante a epidemia de cólera no Rio de Janeiro (1855 - 1856): uma análise preliminar. Rio de Janeiro: História, Ciências, Saúde - Manguinhos, v.I9, supl., dez., 2012. p. 59-79.

LEVY, Paulo Mansur. Conjuntura recente e perspectivas para a economia internacional. Brasília: IPEA, Carta de Conjuntura, n. 50, nota de conjuntura 25, $\mathrm{I}^{\mathrm{O}}$ trimestre de 202I.

MAURO, Frédéric. História econômica mundial I790-1970. 2 ed., Rio de Janeiro: Zahar Editores, 1976.

SANTOS, Luciana dos. Um imenso campo mórbido: controvérsias médicocientíficas sobre a epidemia de cólera-morbo de I855. Rio de Janeiro: História, Ciências, Saúde - Manguinhos, v. 23, n. 2, abr. - jun, 20I6. p. 34I-357.

SECINT. Balança comercial consolidada e séries históricas. Brasília: Secretaria Especial de Comércio Exterior e Assuntos Internacionais, SECINT, 202I. Disponível em: https://www.gov.br/produtividade-e-comercio-exterior/pt-br/assuntos/comercioexterior/estatisticas/balanca-comercial-brasileira-acumulado-do-ano Acesso em: 22 jan 202I.

TAVARES, Luís Henrique Dias. História da Bahia. Io ed., São Paulo: UNESP/Salvador: EDUFBA, 200I. 
WHO - World Health Organzation. WHO Coronavirus dashboard. Disponível em: https://covidı9.who.int/. Acesso em: 22 abr. 202I.

WITTER, Nikelen Acosta. Males e epidemias: sofredores, governantes e curadores no sul do Brasil (Rio Grande do Sul, século XIX). 2007. 276 f. Tese (Doutorado em História). Programa de Pós-Graduação em História, Universidade Federal Fluminense, Niterói/RJ, 2007.

Recebido: 26 de abril de 202I

Aprovado: 13 de julho de 202I 